\title{
Recycling Bio Wastes to Synthesize Nitrogen-doped Highly Porous Activated Carbon Scaffolds for Selenium Stuffing with Superior Electrochemical Properties
}

Muhammad Rashad ${ }^{a}$, Muhammad Asif ${ }^{b}, *$

a School of Materials Science and Engineering, Jiangsu University of Science and Technology, Zhenjiang 212003, Jiangsu, China

${ }^{b}$ Bernal Institute, Department of Chemical Sciences, University of Limerick, Limerick V94 T9PX, Ireland

*Corresponding author E-mail Addresses: muhammad.asif@ul.ie (M. Asif)

\section{Content}

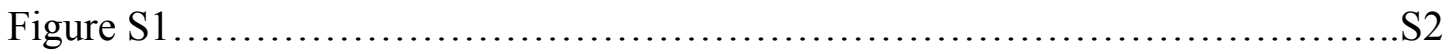

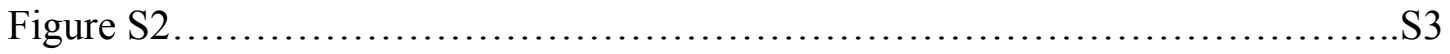

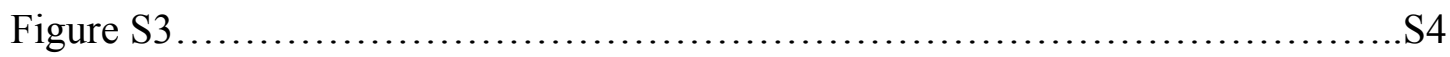

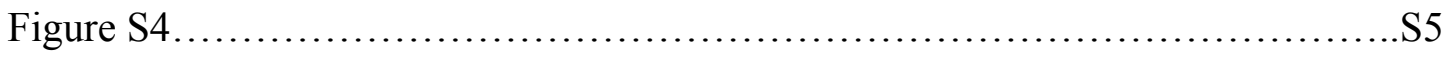

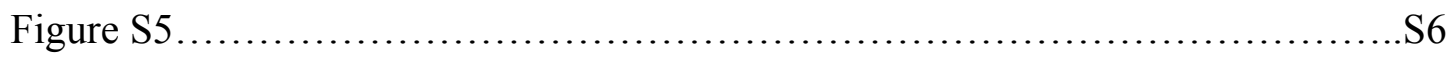

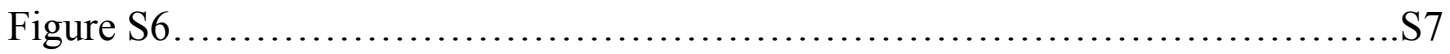

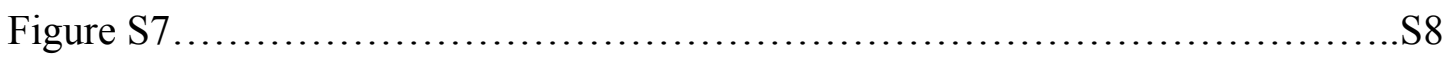



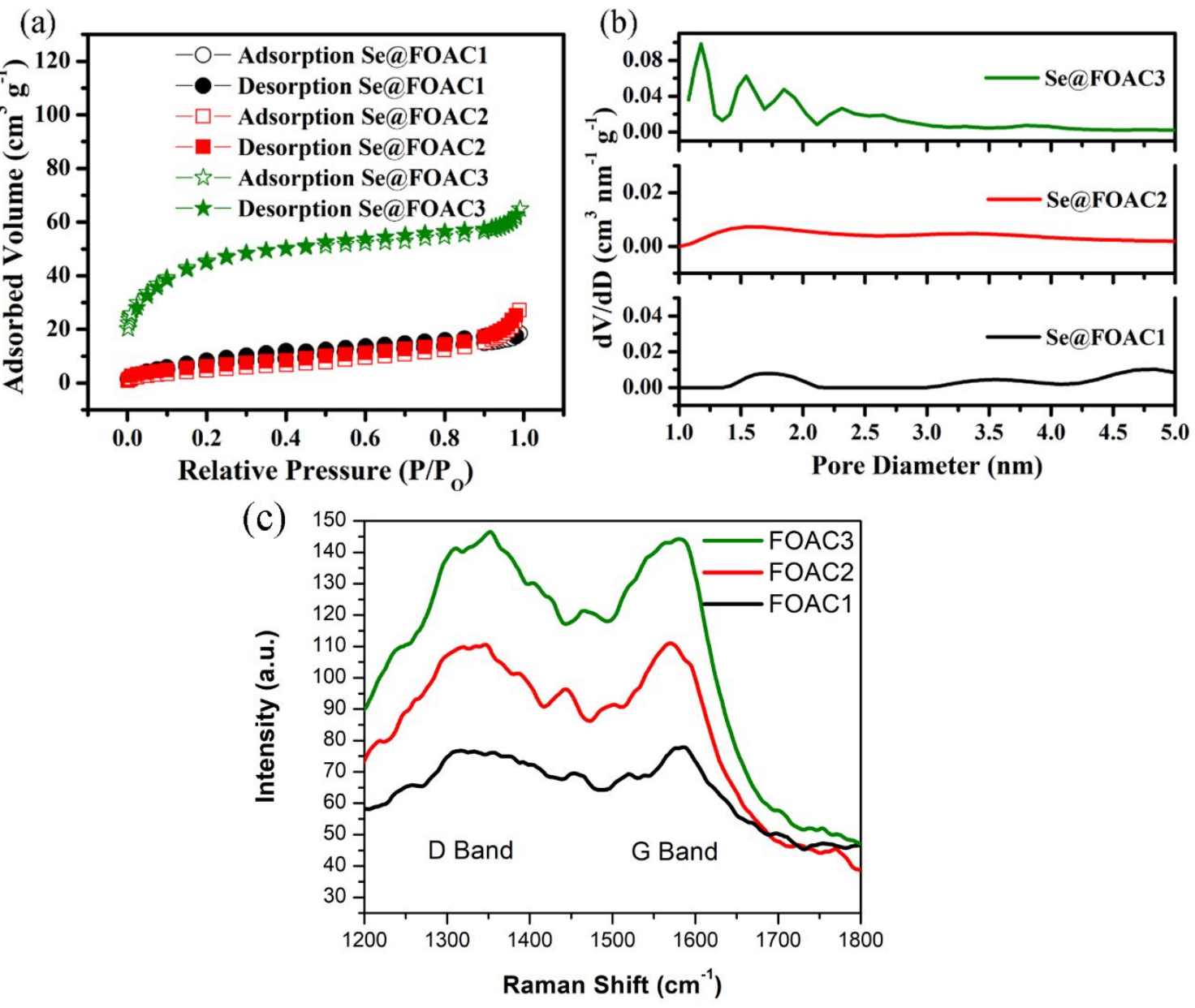

Figure $\mathrm{S} 1$ (a) $\mathrm{N}_{2}$ adsorption-desorption isotherms, (b) pore size distributions of $\mathrm{Se} @$ FOACs, and (c) Raman Spectra of FOACs. 

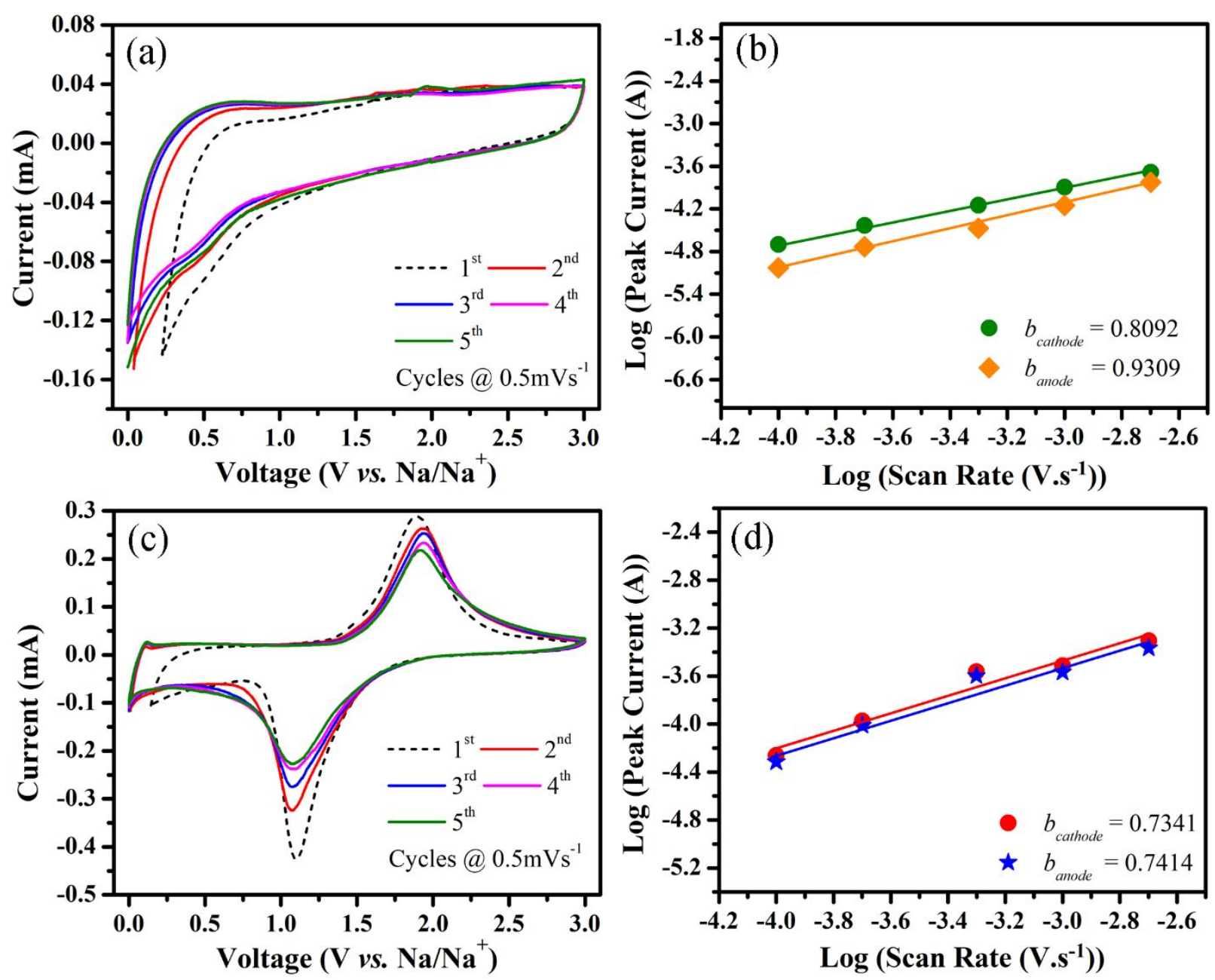

Figure $\mathrm{S} 2$ (a) $\mathrm{CV}$ of FOAC3 at $0.5 \mathrm{mVs}^{-1}$ representing the shape of first five cycles, (b) $b$ value analysis of FOAC3, (c) $\mathrm{CV}$ of $\mathrm{Se} @ \mathrm{FOAC} 3$ at $0.5 \mathrm{mVs}^{-1}$ showing first five cycles, and (d) $b$-value analysis of Se@FOAC3 at different scan rates. 

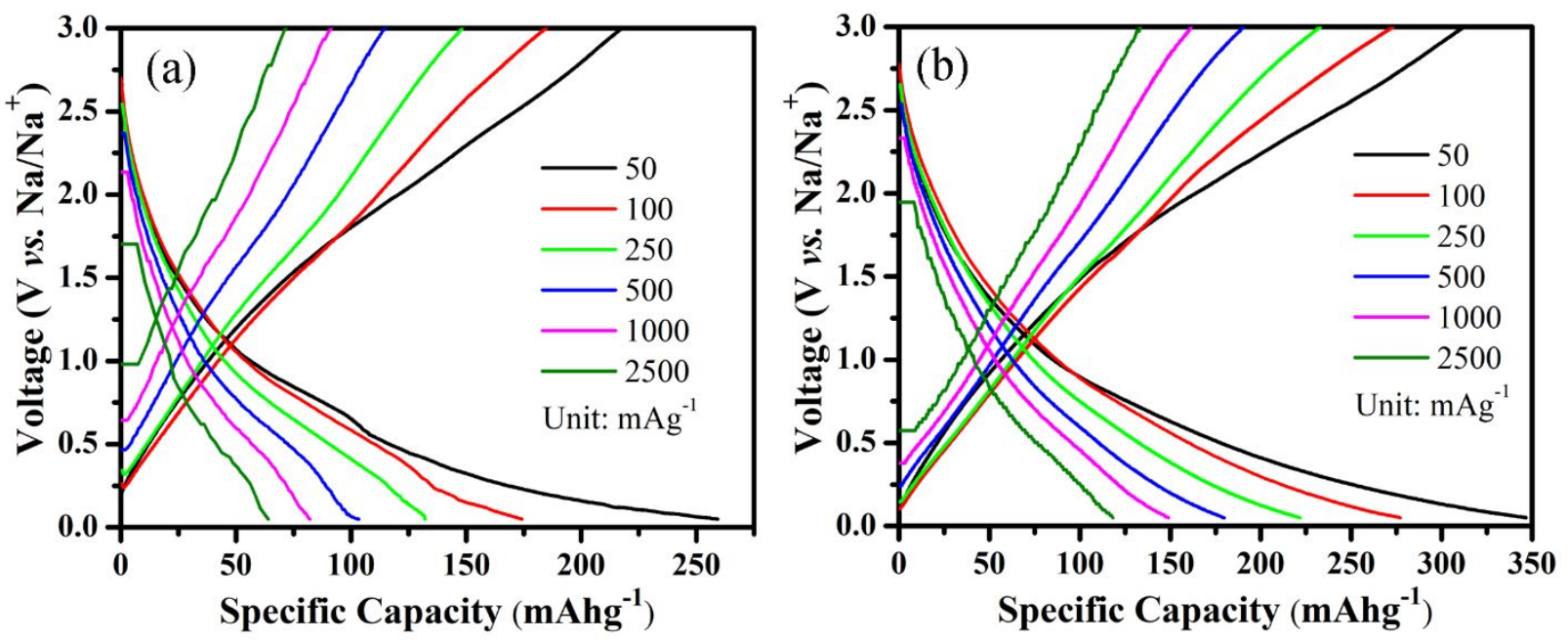

Figure S3 Charging-discharging curves of (a) FOAC1, and (b) FOAC2 at current densities ranging from 50 to $2500 \mathrm{mAg}^{-1}$. 

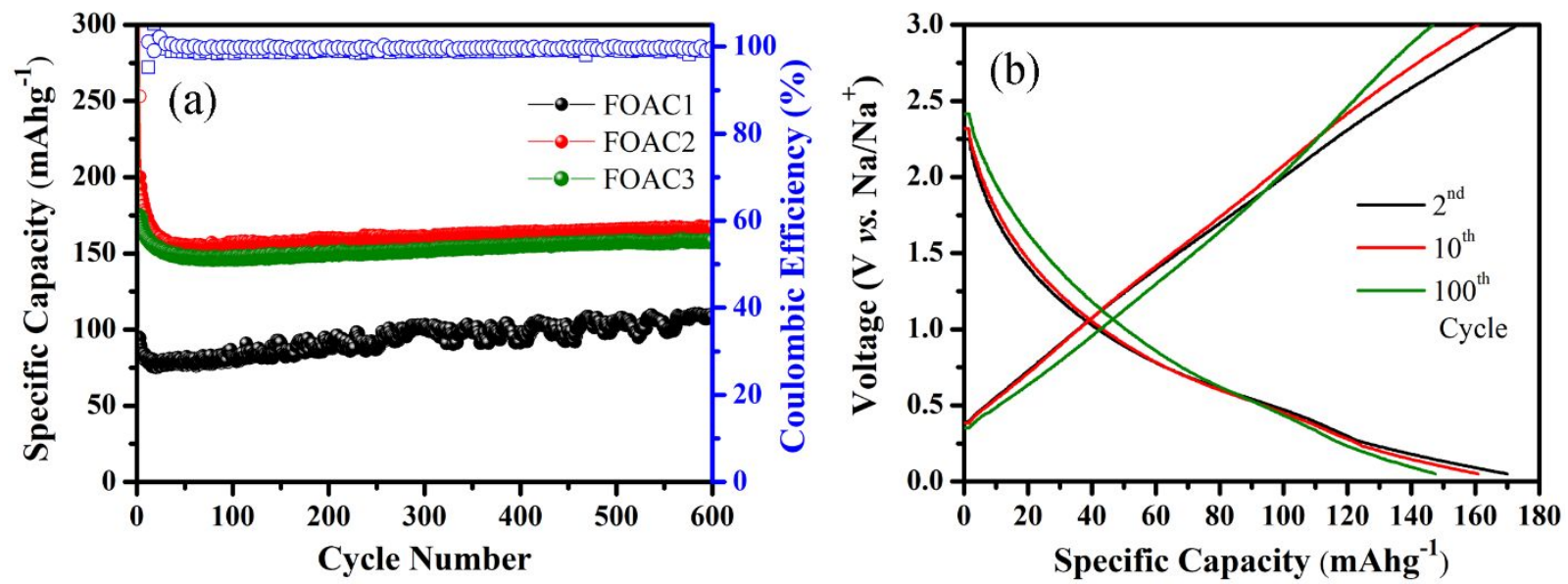

Figure S4 (a) Long-term cycle stabilities of FOAC1, FOAC2, and FOAC3 at $500 \mathrm{mAg}^{-1}$, (b) Shape of $2^{\text {nd }}, 10^{\text {th }}$, and $100^{\text {th }}$ charging-discharging curve of FOAC3 at current density of $500 \mathrm{mAg}^{-1}$. 

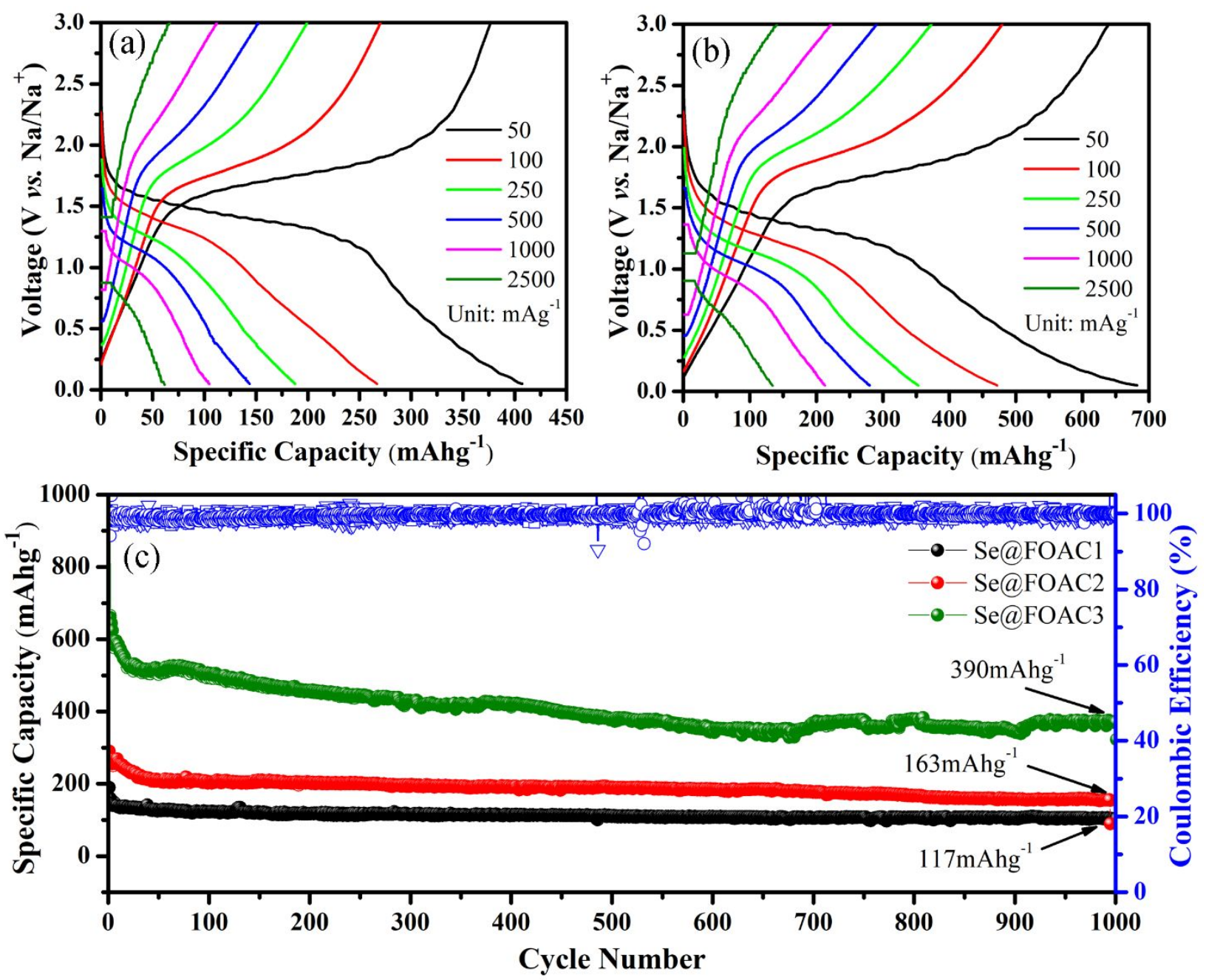

Figure S5 Charging-discharging profiles of (a) Se@FOAC1, (b) Se@FOAC2 at different current densities; and (c) long-term cycle stabilities of Se@FOAC1, Se@FOAC2, and Se@FOAC3 at 500 $\mathrm{mAg}^{-1}$. 

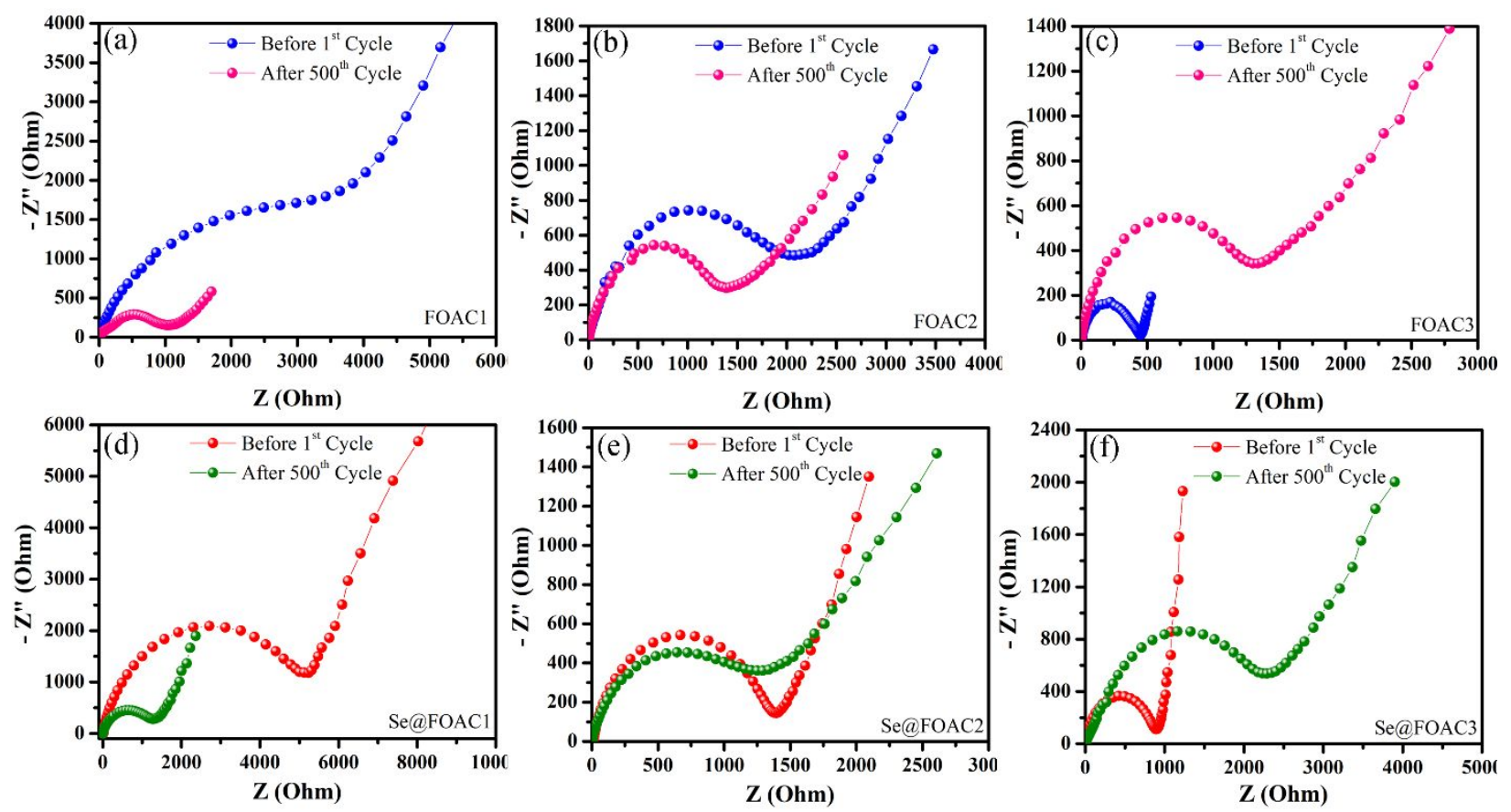

Figure S6 Nyquist plots of FOACs (a-c) and Se@FOACs (d-f) before and after 500cycles in frequency range $0.01-10^{6}$ at $10 \mathrm{mV} \mathrm{AC}$ amplitude. 

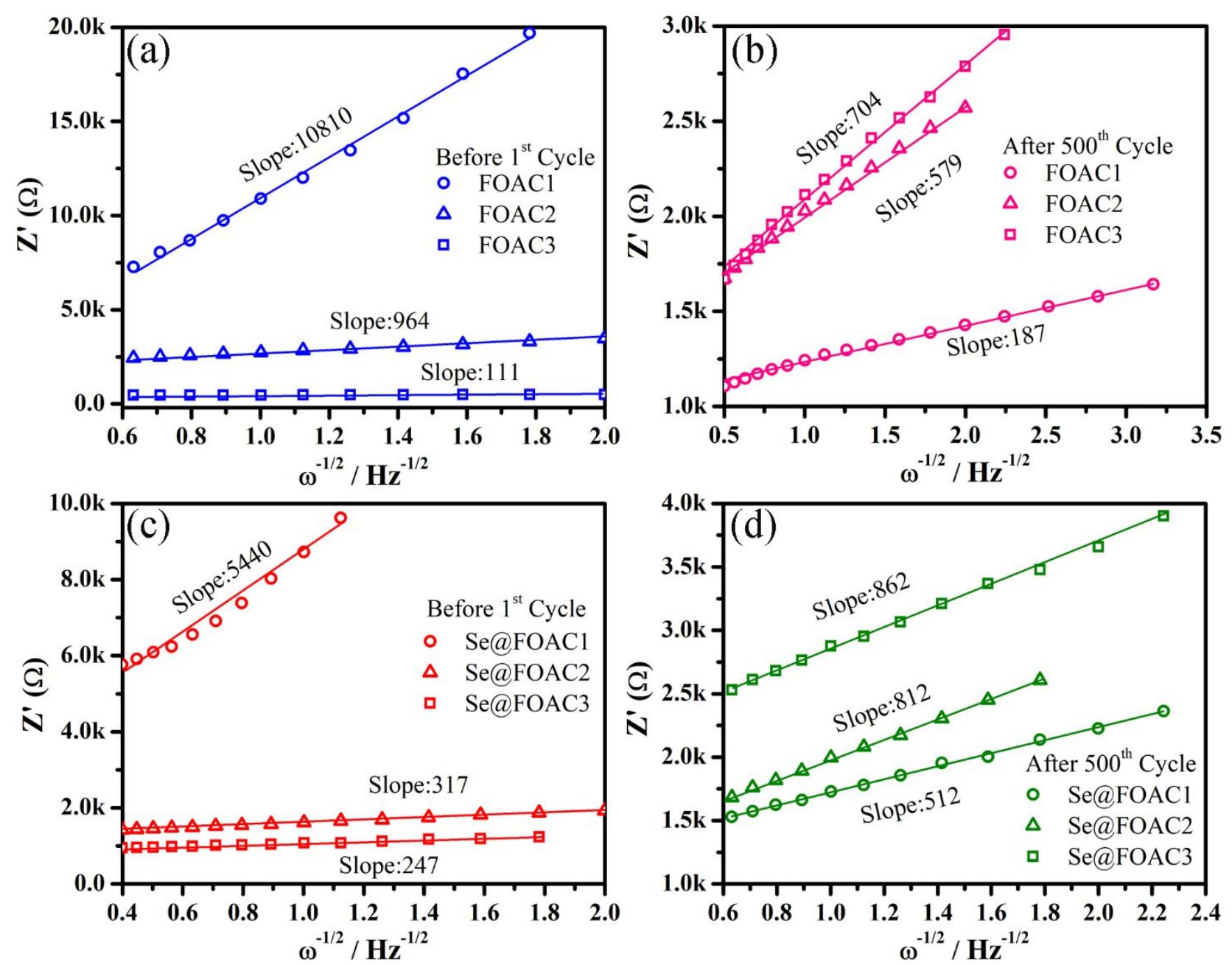

Figure S7 Relationships between $\mathbf{Z}^{\prime}$ and $\boldsymbol{\omega}^{-1 / 2}$ for (a) FOACs before $1^{\text {st }}$ cycle, (b) FOACs after $500^{\text {th }}$ cycle, (c) Se@FOACs before $1^{\text {st }}$ cycle, and (d) Se@FOACs after $500^{\text {th }}$ cycle. 